Revista Eletrônica do Mestrado em Educação Ambiental

Programa de Pós-Graduação em Educação Ambienta1

\title{
Como os estudantes percebem a sustentabilidade na educação superior? Um estudo qualiquantitativo sobre a Universidade Federal do Cariri - CE
}

\author{
Jeferson Antunes ${ }^{1}$ \\ Universidade Federal do Cariri \\ ORCID http://orcid.org/0000-0002-2969-5788
}

Verônica Salgueiro do Nascimento ${ }^{2}$

Universidade Federal do Ceará

ORCID http://orcid.org/0000-0002-4903-5445

Zuleide Fernandes de Queiroz ${ }^{3}$

Universidade Regional do Cariri

ORCID http://orcid.org/0000-0003-3174-4750

Resumo: No contexto acadêmico das discussões acerca da sustentabilidade, diversas instituições de ensino superior (IES) têm aproximado sua missão e visão as discussões sobre a temática. Não obstante, outras IES nascem pautadas nos princípios da sustentabilidade. O presente estudo investiga esse segundo caso, visando compreender através da percepção dos estudantes qual seu entendimento sobre a sustentabilidade, tendo por lócus a Universidade Federal do Cariri (UFCA), uma jovem IES que se insere no contexto do interior cearense, que tem a sustentabilidade como eixo norteador. Os sujeitos desta pesquisa foram 48 estudantes que participaram de entrevista semiestruturada, analisada através do Discurso do Sujeito Coletivo, buscando compreender como se insere o tema na instituição. Compreendemos que a percepção dos estudantes sobre o tema é difusa, fundamentada em mitigar problemas ambientais e redução do consumo, orquestrada em uma racionalidade limitada pelo currículo, mas que apresenta uma pluralidade de discussões.

\footnotetext{
1 Doutorando em Educação Brasileira FACED/UFC, Mestre em Desenvolvimento Regional Sustentável PRODER/UFCA, Licenciatura Plena em História URCA. e-mail: jeferson.antunes@ aluno.ufca.edu.br

2 Doutora em Educação pela Universidade Federal do Ceará (2009) e Pós-Doutora no programa de Pós-Graduação em Psicologia na Universidade Federal do Rio de Janeiro (2015). Faz parte do corpo docente do Programa de PósGraduação. e-mail: vesalgueiro@gmail.com

${ }^{3}$ Graduada em Pedagogia pela Universidade Federal do Ceará (1986), mestrado em Educação pela Universidade Federal do Ceará (1992), doutorado em Educação pela Universidade Federal do Ceará (2003) e pós-doutorado junto ao Programa de Pós-Graduação em Educação da Universidade Federal do Rio Grande do Norte (2014). Professora Colaboradora do Programa de Pós-Graduação. Interdisciplinar em Desenvolvimento Regional Sustentável (PRODER-UFCA). e-mail: zuleidefqueiroz@gmail.com
}

Rev. Eletrônica Mestr. Educ. Ambient. Rio Grande, v. 37, n. 3, p. 138-161, mai./ago. 2020. 
Palavras-chave: Educação Superior. UFCA.Sustentabilidade.

\title{
Como estudiantes de educación sostenibilidad en mayor? A qualiquantitativo estudio de la Universidad de Federal Cariri - CE
}

Resumen: En el context académico de las discusiones sobre sostenibilidad, varias instituciones de educación superior (IES) han acercado su misión y visión a las discusiones sobre el tema. Sin embargo, otras IES nacen con base en los principios de sostenibilidad. El presente studio investiga este segundo caso, con el objetivo de comprender a través de la percepción de los estudiantes cuál es su comprensión sobre la sostenibilidad, teniendo como sede la Universidad Federal de Cariri (UFCA), una IES joven que se inserta en el contexto del campo de Ceará, que tiene sostenibilidad como eje guía. Los sujetos de esta investigación fueron 48 estudiantes que participaron en una entrevista semi estructurada, analizada a través del Discurso del sujeto colectivo, buscando comprender cómo se inserta el tema en la institución. Entendemos que la percepción de los estudiantes sobre el tema es difusa, basada en la mitigación de los problemas ambientales y la reducción del consumo, orquestada en una racionalidad limitada por el plan de estudios, pero que presenta una pluralidad de discusiones.

Palabras clave: Educación superior. UFCA. Sostenibilidad.

\section{How do students perceive sustainability in higher education? A qualitative study on the Federal University of Cariri - CE}

\begin{abstract}
In the academic context of discussions about sustainability, several higher education institutions (HEIs) have brought their mission and vision closer to discussions on the subject. However, other HEIs are born-based on the principles of sustainability. The present study investigates this second case, aiming to understand through the students' perception what is their understanding about sustainability, having as locus the Federal University of Cariri (UFCA), a young HEI that is inserted in the context of Ceará countryside, which has sustainability. as a guiding axis. The subjects of this research were 48 students who participated in a semi-structured interview, analyzed through the Collective Subject Discourse, seeking to understand how the theme is inserted in the institution. We understand that students' perception on the subject is diffuse, based on mitigating environmental problems and reducing consumption, orchestrated in a rationality limited by the curriculum, but which presents a plurality of discussions.
\end{abstract}

Keywords: College education. UFCA.Sustainability.

\section{Introdução}

As Instituições de Ensino Superior (IES) contribuem em seu papel social e de produção do conhecimento, tendo sua centralidade norteada pelo ensino, pesquisa e extensão. Algumas Universidades têm adotado um quarto pilar, a cultura, seja por reconhecer os saberes produzidos para além da ciência ou como estratégia para aproximarse da comunidade no seu entorno.

Pensar o papel da Universidade e da Educação Superior é um passo a autocrítica necessária para rever estratégias e traçar metas, não apenas a Lei de Diretrizes e Bases da Educação (LDB) (LDB n. ${ }^{\circ}$ 9394/96), mas também fóruns de reitores, o Ministério da 
Educação (MEC) e outros fóruns internacionais buscam discutir esses papéis a luz da realidade social.

Entre as diversas iniciativas, a Declaração Mundial sobre o Ensino Superior para o Século XXI, busca formar uma nova visão sobre o Ensino Superior, assentando suas bases na diversidade de oportunidades, pensamento crítico e criatividade, no fortalecimento e participação ao acesso de mulheres ao Ensino Superior e no Desenvolvimento Sustentável como forma de reduzir a disparidade entre países pobres e ricos (DMESSXXI, 1998).

Estes são desafio para além do que assegura a LDB, sobretudo quanto ao Desenvolvimento Sustentável, tema mais recente que a fundação de muitas Universidades. Pactuar ações e ações do conhecimento que visem o bem-estar das atuais gerações sem comprometer as gerações futuras, é um esforço de elevada importância em um contexto político-social onde as IES são alvo da precarização e cobrança pelo produtivismo acadêmico.

Para compreender de que forma se dá esse processo, as seguintes perguntas norteiam nossa pesquisa: Como os estudantes compreendem a sustentabilidade? Como este tema é abordado no cotidiano? Como o Ensino Superior adere a discussão sobre sustentabilidade?

Para tanto, este estudo toma como base a política educacional da Universidade Federal do Cariri (UFCA), no estado do Ceará, que apresenta em sua visão e missão ${ }^{4}$ os princípios do Desenvolvimento Sustentável como eixos norteadores. Investigamos quais concepções diretas e indiretas fazem parte da percepção dos estudantes da IES sobre sustentabilidade.

O objetivo principal desta pesquisa é compreender através da percepção dos estudantes qual seu entendimento sobre a sustentabilidade. Seguindo além, desejamos analisar estes discursos buscando perceber como se dá a inserção do tema na IES estudada e, analisar qual a percepção teórica dos respondentes.

Os estudantes de graduação da UFCA, Campus Juazeiro do Norte, são sujeitos desta pesquisa e a apreensão de seus conhecimentos acerca do Desenvolvimento Sustentável é escopo do estudo. Procederemos com a coleta de dados através de entrevista semiestruturada (FLICK, 2009) analisando estes dados por meio do Discurso do Sujeito Coletivo (DSC) (LEFEVRE; LEFEVRE, 2012), considerando seu conteúdo individual,

\footnotetext{
${ }^{4}$ Missão: Promover conhecimento crítico e socialmente comprometido para o desenvolvimento territorial sustentável, visão: Ser uma universidade de excelência em educação para a sustentabilidade por meio de ensino, pesquisa, extensão e cultura. Fonte: http://www.ufca.edu.br/portal/pei/referencial-estrategico/missao-visao.
} 
para então formar um discurso-síntese a partir da percepção/opinião dos indivíduos participantes.

Compreendemos que a questão da sustentabilidade é um elemento difuso na percepção dos estudantes, sendo influenciada tanto pela política como pelas ações institucionais, e limitada pelo currículo dos diversos cursos de graduação.

\section{Metodologia}

Partindo do princípio que as políticas educacionais, visão e missão de uma IES influenciam a formação de estudantes, busca-se na percepção destes, a compreensão construção do conhecimento acerca da sustentabilidade, objeto do presente estudo. Temos como lócus de pesquisa a UFCA, situada na cidade de Juazeiro do Norte - CE.

A UFCA, criada pela lei N. ${ }^{\circ} 12.826$ do dia 5 de junho de 2013, surge do desmembramento da Universidade Federal do Ceará, no programa de interiorização do Ensino Superior, proposto no Programa de Apoio a Planos de Reestruturação e Expansão das Universidades Federais (REUNI). Sendo uma das instituições públicas de Ensino Superior Federal mais jovens do país, conta com cinco campi nas cidades de Juazeiro do Norte (sede), Crato, Barbalha, Icó e Brejo Santo (ANTUNES; RIBEIRO; ARRAIS; MOREIRA, 2015).

Estudantes escolhidos para esta pesquisa são da UFCA - Campus de Juazeiro do Norte, onde temos 1686 estudantes ativos matriculados em 2016. A distribuição por curso é: Administração Pública (152), Administração (189), Biblioteconomia (112), Comunicação Social (162), Design de Produtos (106), Engenharia Civil (434), Engenharia de Materiais (238), Filosofia (144), Música (149).

Definido o número total de estudantes, a menor amostra possível do universo serão três indivíduos (EDWARDS; HOLLAND, 2013; FLICK, 2009). Tomando-os como base, utilizamos uma distribuição da frequência relativa proporcional, a partir da média de possíveis entrevistas (CASTANHEIRA, 2012), resultando na definição de amostra a quantidade de 48 estudantes destes diversos cursos de graduação com a seguinte divisão: Administração Pública (5), Administração (5), Biblioteconomia (3), Comunicação Social (5), Design de Produtos (3), Engenharia Civil (12), Engenharia de Materiais (7), Filosofia (4) e Música (4).

Para a realização desta pesquisa utilizamos da apreensão da realidade a partir de entrevistas com os estudantes, utilizando entrevista semiestruturada (FLICK, 2009), para 
uma análise dos saberes que estes constituem, ao longo da trajetória acadêmica e dos diversos cursos de graduação, o conhecimento acerca dasustentabilidade. Optamos por entrevistar apenas estudantes que tenham, ao menos, um ano de graduação completos na instituição, essas entrevistas foram realizadas entre dezembro de 2016 e fevereiro de 2017. Os questionamentos realizados são apresentados na legenda dos quadros de síntese.

Os dados então apreendidos durante as entrevistas foram transcritos, e posteriormente analisados através da metodologia do DSC. Este método analisa o discurso dos participantes sobre o tema, considerando seu conteúdo individual, para então formar um discurso-síntese a partir da percepção/opinião dos indivíduos participantes fornecendo, além de dados qualitativos, dados quantitativos (amplitude e intensidade ou força) que nos auxiliam a compreender o quadro geral para além dos dados específicos (LEFEVRE; LEFEVRE, 2012).

\section{Ensino superior e sustentabilidade}

No artigo 43 da LDB, está definido o papel do Ensino Superior como o desenvolvimento da ciência e do pensamento crítico, com estimulo a cultura e o desenvolvimento contínuo da sociedade através de conhecimentos que constituem seu patrimônio imaterial e a inserção para o mercado de trabalho (LDB, 1996).

Como espaço institucionalizado, a Universidade é um reflexo das condições sociais contemporâneas, com uma diversidade de ideias e contradições em seu interior, a pluralidade entre ensino, pesquisa, extensão e cultura evidenciam seu papel na construção do conhecimento (ANTUNES; NASCIMENTO; QUEIROZ, 2017), é "dentro da universidade como instituição, encontramos opiniões, projetos e atitudes conflitantes, que refletem as divisões e contradições da sociedade como um todo" (BERNHEIM; CHAUÍ, 2008, p. 18). Nesse interim, a Universidade, como campo de produção de saberes, não pode ser dissociada da sociedade.

A instituição, como parte da sociedade, deve refletir sobre o desenvolvimento e o fim das desigualdades sociais. Na Declaração Mundial sobre o Ensino Superior para o Século XXI, são discutidos os rumos da Educação Superior, tendo como papel "compartilhar do conhecimento, a cooperação internacional e as novas tecnologias [que] podem oferecer oportunidades novas para reduzir esta disparidade” (DMESSXXI, 1998). O Desenvolvimento Sustentável, endógeno, pensado a partir das necessidades sociais de tal forma a contribuir para com desenvolvimento das potencialidades humanas é parte 
integrante da agenda da educação superior, exigindo ética, construção crítica do conhecimento, articulação teórico-prática; respeitando a cultura e o meio ambiente (BERNHEIM; CHAUÍ, 2008; DMESSXXI, 1998).

A partir do exposto, o papel do Ensino Superior não se limita a reprodução de conhecimentos e conteúdo, ela medeia a construção do conhecimento com a realidade social, contribuindo para o desenvolvimento de uma sociedade plena em seus potenciais. Para isso, pensar o desenvolvimento socialmente includente e sustentável é um caminho para estabelecer uma sociedade mais justa, "as missões e valores fundamentais da educação superior, em particular a missão de contribuir para o desenvolvimento sustentável e o melhoramento da sociedade como um todo, devem ser preservados, reforçados e expandidos" (DMESSXXI, 1998) em um diálogo aberto e participativo, reconhecendo os saberes, de forma colaborativa, construindo conhecimentos que visem o bem-estar e a consolidação dos direitos humanos.

Nesse interim é necessário um projeto político de instituição, legitimo e autônomo, que possa contribuir com um projeto de nação que assegure mudanças qualitativas para a sociedade (BERNHEIM; CHAUÍ, 2008, p. 27). Essa busca pela identidade institucional faz parte da reflexão do papel social do Ensino Superior,

a ser seguido pela educação superior contemporânea, a saber, o paradigma do desenvolvimento humano endógeno, ao mesmo tempo humano e sustentável, o que significa um desenvolvimento baseado em nossas próprias forças produtivas, nas nossas capacidades e na competitividade a serviço da dignidade do ser humano; desenvolvimento que respeite o direito das futuras gerações de satisfazer suas necessidades, e que preserve a identidade cultural dos nossos povos (BERNHEIM; CHAUÍ, 2008, p. 16).

Com esse compromisso crítico, pautado nas necessidades e na realidade social, variadas instituições se construíram, sejam elas públicas ou privadas, com missões, visões e valores que vão além de sistematizar conhecimento. Existe uma clara necessidade da contribuição destas instituições, através da sua leitura de mundo, que possam contribuir para a mudança qualitativa tão necessária ante a crise ambiental, mediando saberes e práticas, reconhecendo outros saberes, na emergência de seu papel social (ANTUNES; NASCIMENTO; QUEIROZ, 2018).

\section{Percepções sobre a sustentabilidade}


Para compreendermos de forma mais clara como a Educação Superior pode contribuir na formação de consciência ante a crise ambiental, a partir do conceito de sustentabilidade, escolhemos por entrevistar estudantes da UFCA, uma instituição de Ensino Superior que tem em sua missão, visão e valores o comprometimento com o Desenvolvimento Sustentável.Tal escolha é acertada, uma vez que são os estudantes a maior parte da sociedade que se faz representada na instituição, o ensino, portanto, é a forma e o contato principal com temas tão necessários para o século XXI.Quanto ao primeiro contato com o termo sustentabilidade, a partir das entrevistas com os estudantes da UFCA, apresentamos as seguintes categorias de análise e discursos síntese:

Quadro 1: Categorias de análise e discursos da pergunta: Você já teve algum contato com a ideia de sustentabilidade? Se sim, nos fale como foi o seu primeiro contato; caso contrário, por que isso não ocorreu?

\begin{tabular}{|c|}
\hline Categorias de análise -Discursos \\
\hline Formação técnica - Eu tive contato com a sustentabilidade quando fiz um curso técnico de assistente administrativo. \\
\hline $\begin{array}{l}\text { No Trabalho - Eu tive contato com um projeto de sustentabilidade há uns dois anos, quando foi proposto na empresa } \\
\text { onde eu trabalhava. }\end{array}$ \\
\hline $\begin{array}{l}\text { Disciplina de graduação na UFCA - O meu primeiro contato foi aqui no curso de graduação em uma disciplina, durante } \\
\text { a aula da graduação, nas disciplinas de Marketing, Engenharia Ambiental, Desenvolvimento Sustentável. Minha primeira } \\
\text { ideia foi quando eu estava fazendo minha monografia. }\end{array}$ \\
\hline $\begin{array}{l}\text { Na mídia - Meu primeiro contato foi através da mídia mesmo, da televisão, mais com relação a programas de TV } \\
\text { ensinando como se faz, como se utiliza; reportagens, filmes, documentários, tipo um trabalho de conscientização, na } \\
\text { mídia você vê essa questão da sustentabilidade. Também redes sociais, facebooks, youtubes. }\end{array}$ \\
\hline $\begin{array}{l}\text { Na Escola - Desde a escola estudo um pouco sobre isso, porque é uma questão bastante importante, tive contato na } \\
\text { escola onde estudei; havia formação de texto e nesse debate sobre geopolítica, geografia, era coisa mais context ualizada; } \\
\text { trabalho de conscientização e mostra ambiental na escola. Aconteceu na época da escola, com os professores à explicar, } \\
\text { introduzindo esse conteúdo, na sala, na disciplina de geografia (que geralmente é o que vem tratar isso), história e } \\
\text { ciências, na escola era um assunto muito trabalhado, imagino que tive as primeiras noções do que seria sustentabilidade } \\
\text { quando a gente estuda ecologia na escola. }\end{array}$ \\
\hline $\begin{array}{l}\text { Evento de conscientização em espaços públicos - Tive contato com a ideia da sustentabilidade através de palestras na } \\
\text { escola de ensino médio; uma palestra do debate do fórum das águas que houve aqui na UFCA e na semana do meio } \\
\text { ambiente em uma oficina sobre sustentabilidade. }\end{array}$ \\
\hline $\begin{array}{l}\text { Consumo de produtos - Em uma loja de Juazeiro do Norte que trabalha com questão de pallets para fazer móveis, seja } \\
\text { cadeiras, seja banco, seja cadeira, independente do móvel. }\end{array}$ \\
\hline $\begin{array}{l}\text { Outras formações acadêmicas - Em uma pós-graduação em Logística tive uma disciplina de Logística Sustentável, } \\
\text { onde a gente viu alguns conceitos de sustentabilidade e no curso de Engenharia de Energias Renováveis. }\end{array}$ \\
\hline o Setor - Tive esse primeiro contato, que foi na adolescência, com essa questão da sustent \\
\hline
\end{tabular}

Fonte: Elaborado pelos autores com dados da pesquisa.

Analisando estes discursos, a categoria trabalho aparece inserida, bem como educação e mídia, sendo os três canais mais asseverados pelos participantes da pesquisa. A importância da discussão sobre sustentabilidade nos espaços educativos escolares impactou a vida dos participantes, uma vez que de pronto retomaram tal memória, sendo as atividades escolares muito importantes na construção de uma consciência ecológica, na formação de um sujeito, onde a educação faz parte de sua história de vida, tais 
ensinamentos podem se desdobrar no entendimento da valorização do ecológico para a valorização da vida e um projeto de sociedade mais justo (CARVALHO, 2017).

Vale ressaltar ainda que, uma pequena parcela dos estudantes obteve contato inicial com o tema na própria UFCA e em outras graduações, seja a partir de disciplinas de graduação ou eventos, sendo papel da Universidade o fomento a discussão (DMESSXXI, 1998).

Não é de se estranhar que a mídia seja citada como fonte inicial de acesso ao primeiro contato sobre o tema sustentabilidade, uma vez que, pós Rio-92, variados programas sobre ecologia foram ao ar (restando poucos no presente) sendo uma pauta global das discussões resultante das conferencias globais.

A categoria trabalho denota o acesso prático sobre o tema, evidenciada nas categorias de análise consumo, trabalho e ONG; tal assertiva nos dá indícios que, na região do cariri, algumas instituições tem discutido e se projetado ao consumo consciente e ao campo de produção dita sustentável.Para fins de generalização das ideias, apresentamos os seguintes dados complementares, baseados nas entrevistas realizadas:

Gráfico 1: Categorias de análise e discursos da pergunta: Você já teve algum contato com a ideia de sustentabilidade? Se sim, nos fale como foi o seu primeiro contato; caso contrário, por que isso não ocorreu?

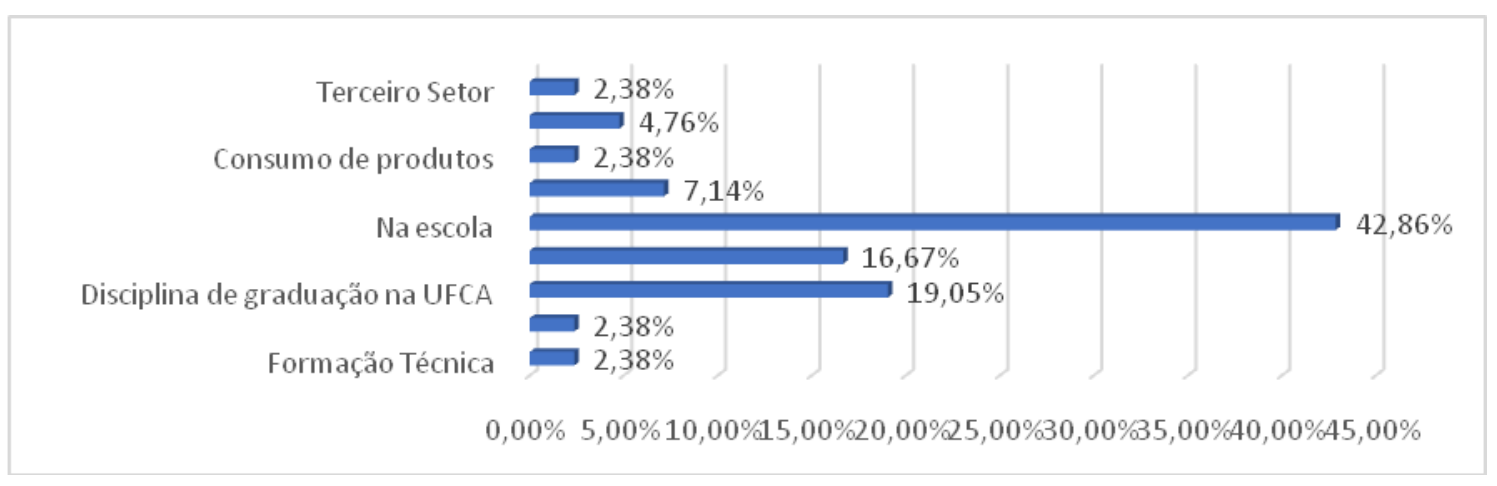

Fonte: Elaborado pelos autores com dados da pesquisa.

A categoria escola se encontra com alta amplitude e grande força no todo da discussão, sendo a mais apresentada nos discursos síntese e estando amplamente difundida no todo. A categoria disciplinas de graduação na UFCA se apresenta compartilhada no todo, com baixa amplitude e grande força, sendo considerada pelos entrevistados, mas presente em um pequeno número de relatos, o mesmo acontece com a categoria mídia. $\mathrm{O}$ 
restante das categorias analisadas estão dispersas no todo, com baixa amplitude e força, o que nos sugere experiências pontuais por parte dos estudantes.

Compreendemos, a partir destes dados, que o campo da educação é o que mais oportuniza o primeiro contato com o tema sustentabilidade, principalmente a escola, onde ressaltamos seu papel na promoção da formação voltada ao campo da educação ambiental. Em nosso segundo questionamento desejamos saber dos estudantes se a UFCA tem alguma influência para seu entendimento sobre sustentabilidade, as seguintes categorias de análise apresentam os discursos síntese dos participantes:

Quadro 2: Categorias de análise e discursos da pergunta: Existe, na sua opinião, alguma influência da Universidade Federal do Cariri sobre sua compreensão acerca da sustentabilidade? Se sim, de forma isso ocorre; caso contrário, por que você tem essa opinião?

\section{Categorias de análise -Discursos}

Não me influência - Não vejo que a universidade tenha influencias sobre o meu pensamento acerca da sustentabilidade, simplesmente durante minha graduação não foi um tema que foi trabalhado, eu nunca vi divulgação, nem nada a respeito do tema; até agora eu nunca vi nada relacionado palestras, debates, em cima desse tema, se existe alguma influência da universidade eu desconheço. Pelo menos se há, ela não é divulgada para os alunos ou não é transparente para os alunos, porque eu nunca vi nenhuma iniciativa da Universidade para promover a sustentabilidade. Eu acho que por falta dos professores, eles poderiam adotar isso nas disciplinas, nenhuma cadeira que eu paguei até hoje e nem palestra e nenhuma ação, a gente vê pouco isso tanto no curso quanto no dia-a-dia da universidade. Na minha opinião em relação a sustentabilidade eu acho que é a primeira vez que eu estou sendo questionada em relação a isso. Acho que não tem esses debates realmente na universidade.

Sim, superficialmente - Foi mencionado algumas vezes em algumas cadeiras que eu paguei, mas nunca me aprofundei no tema dentro da universidade, nas disciplinas que estou vendo agora, vejo alguns problemas relacionados, algumas cadeiras mais teóricas que a gente tem um leve contato, não é uma coisa que marque tanto a questão da sustentabilidade. Eu tô pensando aqui durante a minha graduação e por exemplo a gente só tá meio estudando essas questões sustentáveis, porque de certo modo a questão do tema em si, do que é, de como se dá, mais ou menos essa noção eu tive o contato a partir dessa questão dessa vivência com a universidade. A questão da universidade incentivar a sustentabilidade não é uma coisa tão extraordinária assim no sentindo de "ah, tá fazendo um projeto", embora tenha pós-graduação em sustentabilidade, as contribuições do mestrado conseguem chegar pouco na graduação, consegue dialogar muito pouco com os estudantes da graduação, eu ainda acho tudo muito vago. Existem projetos dentro da universidade que tentam trazer um pouco dessa consciência, que tentam voltar para isso, são poucos e são de certa forma limitados a alguns cursos que possam ter áreas ou vieses parecidos. Os próprios documentos da universidade como planejamento estratégico, a sustentabilidade tá presente, só que o que mais me chama atenção é que existe uma disparidade entre o que tá escrito nos documentos e nas próprias estruturas físicas da universidade, então ela influência no sentido de dizer que preza pela sustentabilidade, mas em termos práticos ela não acontece, ou não acontece como deveria ocorrer.

Sim, de forma mais aprofundada - Sim, a faculdade me proporcionou um contato maior com pessoas que têm um conhecimento abrangente sobre o assunto, que me mostram e me dão suas ideias, me falam sobre a sustentabilidade e como agir, eu tive uma melhor compreensão a partir da minha inserção na academia. A universidade sempre influência na nossa formação, seja positiva ou negativamente, nós estamos em uma universidade que tem um Mestrado em Desenvolvimento Regional Sustentável, ou seja, naturalmente ela tem que exercer a mínima influência sobre a formação e o entendimento de sustentabilidade nas pessoas que à frequentam, evidenciando qual o real sentido da sustentabilidade, o que é sustentabilidade de fato, quais são as áreas de estudo e de que maneira nós estamos vivendo essa sustentabilidade, se nós estamos entendendo ou deturpando o sentido da sustentabilidade, e para se adequar aos nossos sentidos, aos nossos meios ou aos nossos desejos. Uma disciplina que paguei me ajudou muito, me instigou muito a pensar sobre a finalidade do meu lixo, sobre esse processo de consumo, de bens de consumo que são sempre descartados, então eu aprendi a me policiar mais quanto ao fim do lixo que produzo em minha casa. Tive a oportunidade de cursar uma disciplina que é voltada para essa parte de sustentabilidade, o profissional hoje nessa área tem que pensar tudo através da sustentabilidade, a questão dos materiais, se ele vai ferir ou não o meio ambiente e de que forma ele pode ser reaproveitado quando for descartado, a gente precisa também pensar um pouco no planeta e em como retribuir. Então aqui na universidade você alarga seus horizontes sobre essa questão de sustentabilidade dentro das disciplinas.

Sim, através de eventos - Sim, acho que a faculdade contribui porque ela fornece muitas palestras, encontros e feiras, assim contribui para o estudante compreender de forma facilitada.

Fonte: Elaborado pelos autores com dados da pesquisa.

Rev. Eletrônica Mestr. Educ. Ambient. Rio Grande, v. 37, n. 3, p. 138-161, mai./ago. 2020. 
Para a maioria dos estudantes a UFCA exerce alguma influência sobre seu entendimento sobre a sustentabilidade, seja de forma aprofundada, citando inclusive o programa de Pós-Graduação em Desenvolvimento Regional Sustentável da IES, bem como disciplinas sobre o tema, e sua importância para atuação profissional, isto demonstra que a instituição exerce uma forte influência para estes estudantes, mas de variadas formas. Os participantes questionam, no entanto, a pouca presença do tema, a muitos dos respondentes o tema surge em vaga lembrança, por isso a divisão proposital dos níveis de influência, inclusive, especificamente nos eventos.

Sendo uma das missões da IES, como instituição educativa, os espaços de discussão devem ser variados e profícuos ante a emergência do tema (DMESSXXI, 1998), no entanto, a institucionalização por meio de disciplinas pode ser uma das causas de dispersão, não sendo existente em todos os cursos analisados, uma vez não sendo componente curricular obrigatório se entende essa dispersão na influência do todo.

Essa necessidade da mudança e institucionalização curricular pode auxiliar a uma melhor compreensão do tema, "a partir da mudança do comportamento dos indivíduos e da conscientização dos mesmos para essas questões, a mudança nos currículos escolares seria uma forma de tornar a Educação Ambiental mais efetiva" (TRAVASSO, 2001, p. 04). Não obstante, a presença de eventos que tratem do tema também é sentida, uma vez que é citada pelos respondentes como importante.

Estabelecemos como fundamental, a partir destas percepções, o currículo e os eventos, justamente pelos discursos que demonstram não haver influência, uma vez que estes assumem não ter uma divulgação quanto a eventos, o que os torna desconhecidos ao público e também, a ausência nas disciplinas de graduação. A partir do gráfico abaixo temos uma compreensão mais geral destes discursos síntese:

Gráfico 2: Categorias de análise e discursos da pergunta: Existe, na sua opinião, alguma influência da Universidade Federal do Cariri sobre sua compreensão acerca da sustentabilidade? Se sim, de forma isso ocorre; caso contrário, por que você tem essa opinião?

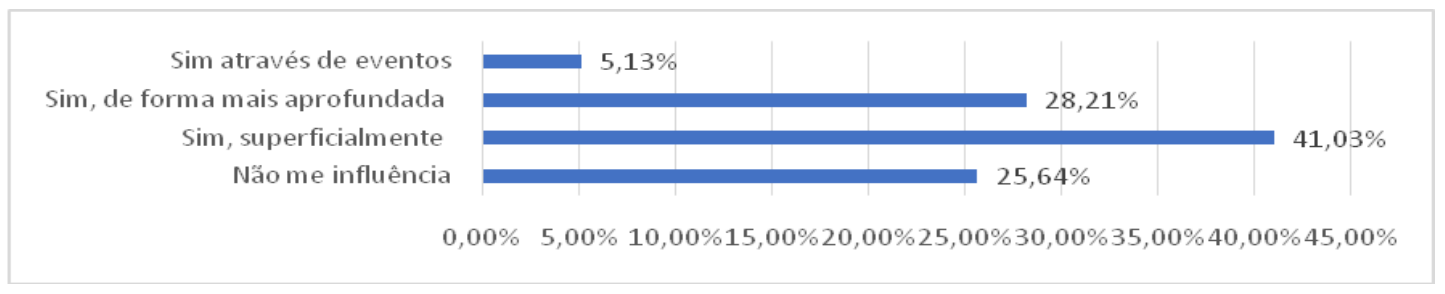

Fonte: Elaborado pelo autor com dados da pesquisa.

Rev. Eletrônica Mestr. Educ. Ambient. Rio Grande, v. 37, n. 3, p. 138-161, mai./ago. 2020. 
Para uma ampla maioria o tema é tratado de forma superficial, com grande força e amplitude, fato que demonstra a necessidade de repensar o plano de ensino-aprendizagem em uma instituição que tem como objetivo tratar do tema. A percepção sobre a influência é satisfatória, onde ampla maioria percebe alguma influência, as próprias disciplinas de graduação estão convergindo a isso, mas com baixa amplitude e alta força, o que nos leva a entender que apenas parte dos respondentes tiveram acesso a este conteúdo disciplinar. Um outro grupo, também com baixa amplitude, mas alta força, concentra percepções que afirmam não existir influência da instituição, convergindo nas questões de currículo e eventos.

Quando questionamos os estudantes acerca da presença do tema sustentabilidade nas disciplinas de graduação, observamos os seguintes discursos síntese e categorias de análise.

Quadro 3: Categorias de análise e discursos da pergunta: Na sua opinião, a ideia da sustentabilidade é trabalhada em sua graduação? Se sim, de que forma isso ocorre; caso contrário, por que não?

\begin{abstract}
Categorias de análise -Discursos
Não, tenho que busca extra sala - Não é trabalhado na minha graduação. Isso é algo que se eu quiser ter uma compreensão devo buscar por meios extra sala, porque os professores não proporcionam esse tipo de aprendizado a respeito da sustentabilidade.

Não, não é abordado - A ideia da sustentabilidade não tem sido abordada nas ultimas matérias que tenho estudado, não foram abordadas dentro da minha graduação, não sei porque. Dentro da graduação esse não é um tema recorrente, até agora eu não vi nada que seja voltado, a gente trabalha muito com factual, cotidiano. Quando é para se falar de sustentabilidade, que é um tema muito amplo, muito denso, já é uma coisa totalmente diferente, é algo normativo, não algo estimulado pelos professores ou pelas disciplinas em si.

Sim, voltada a condições específica do curso - Ela ocorre de forma direta, a gente trabalha com produtos e tipos de material, e tem que pensar tudo na questão da sustentabilidade, se vai demandar um tipo de energia que seja sustentável, renovável, questão dos materiais sustentáveis, materiais que podem ser reaproveitados; o transporte, até quando o produto vai ser descartado, também envolve o lixo e tudo mais, tem que se importar um pouco com essa questão ambiental, a gente trabalha com a reciclagem de objetos que já foram descartados que a gente utiliza pra criar. A primeira preocupação de todos os professores é expor a respeito da sustentabilidade, o que é o certo e o que é o fácil, que hoje muitas vezes se trabalha mais o fácil e não o certo. A sustentabilidade hoje é um marketing muito forte, ou seja, faz as empresas ter mais lucro, então por isso que é bem trabalhado no nosso curso. Os professores, eles tentam destacar algumas condutas que a gente deve observar pra desenvolver um trabalho sustentável que é bastante trabalhada em várias cadeiras específicas pra conversar sobre esse assunto, aí nessas cadeiras tem o debate com relação a sustentabilidade. Esse é um assunto do meu campo, o desenvolvimento sustentável da cidade, do país, do estado; é um assunto de cunho social, acho que todas as pessoas deveriam se interessar durante debates em salas de aulas, disciplinas que são mais tratando da parte mais humana da sociedade, sempre envolve sim o meu curso no caso. A sustentabilidades é trabalhada em algumas disciplinas, como eu já falei, que a professora trata muito o assunto de sustentabilidade, que ela passa até prova sobre o assunto e a gente aborda muito isso na sala.

Não, por falta de tempo e espaço - Não, não vejo que ela é trabalhada. Eu acho que é questão do espaço, do tempo que não permite que muitos professores acabem passando esse tipo de assunto. A gente não tem nenhuma cadeira nessa área, então, por isso, são pequenas citações que são feitas, no resto da graduação não mais foi discutido sobre o assunto. Não foi trabalhado, porque é um tema um tanto quanto controverso na minha área.

Sim, formação da consciência - Sim, a disciplina e alguns problemas que a gente precisa pensar me ajudou muito, me instigou muito, a pensar sobre a finalidade do meu lixo, sobre esse processo de consumo, de bens de consumo que são sempre descartados, ao crescimento urbano e à sustentabilidade; então eu aprendi a me policiar mais quanto ao fim do lixo que produzo em minha casa.

Sim, de forma pouco aprofundada - Sim, de forma teórica em uma cadeira e em alguns congressos que a professora já organizou, a professora aborda muito sobre esse tema, sobre a sustentabilidade, a gente ouve a palavra, mas assim, o ensinamento mesmo pra gente ver sustentabilidade, entender o que é sustentabilidade e tal, é tudo muito por cima, muito
\end{abstract}


por cima. Eu acho que ocorre pouco em relação a outros temas, os sociais, a sustentabilidade meio que fica assim em terceiro plano, se estuda é muito pouco, não diretamente, mas sempre tem conversa, palestrantes, sempre envolve sim o meu curso no caso. Em algumas aulas parece como assunto transversal, já alguns professores pegam muito a questão da sustentabilidade, a gente tem apenas uma cadeira voltada para essa área, as demais a gente trabalha em torno, mas não diretamente, é pouco espaço para se discutir sustentabilidade ambiental, mas esse debate não é muito forte, de fato a sustentabilidade é bastante pontual na nossa graduação; ela é trabalhada de maneira muito rasa, muito superficial, tanto no quesito ambiental como no quesito real e abrangente do todo.

Sim, mas não dialoga com outras disciplinas - A gente vê um conceito de sustentabilidade em uma disciplina que fica só naquela disciplina, não é reaplicado em outras disciplinas, em outras áreas de estudo que poderiam contribuir pra o conhecimento mais consolidado nessa área.

Fonte: Elaborado pelos autores com dados da pesquisa.

Quantos as disciplinas de graduação os discursos divergem, com grupos de estudantes que afirmam ter acesso, mesmo que precário, necessitando de uma complementaridade em seus estudos, outros têm uma percepção de acesso curricular. Existem, ainda, os que afirmam não ter acesso nas disciplinas, seja por falta de tempo pedagógico ou de inserção no currículo.

Entre as categorias que apresentam ter algum acesso a discussão via disciplinas de graduação, as condições específicas do curso, ou seja, sua presença no currículo é apontada, estando voltadas a tecnologia e seus usos sustentáveis. Duas questões preocupantes estão ligadas a superficialidade dos temas nas disciplinas, uma vez que, para os estudantes, apenas aspectos teóricos são levantados, faltando diálogo com outras disciplinas, que acaba tornando a discussão muito pontual.

Não é o bastante, tratando da emergência desta discussão, a inserção parcial e eminentemente teórica destas disciplinas, elas necessitam estar interligada a realidade institucional para apresentar resultados realmente mais expressivos na formação (GOMES, 2001), onde compreendemos ainda que, por suas fortes características interdisciplinares a pontualidade nas disciplinas de graduação não convergem ao que de fato se compreende a sustentabilidade quanto campo de pesquisa (FLORIANI, 2010).

Alguns estudantes manifestam em suas percepções a falta de tempo e espaço, a necessidade de auto estudos e outros simplesmente dizem que o tema não é abordado, o que nos retoma ao problema de currículo. Se em sua missão e visão a UFCA se propõe a discutir a temática, sendo este um dos eixos da instituição, tais acepções demonstram o quão, no nível do discurso, ainda está o tema.São necessárias ações diretivas ao processo de ensino-aprendizagem, não apenas a noção de inserção curricular e eventos esporádicos, a instituição carece de estudos sobre os pontos aqui abordados. Para uma melhor compreensão geral, segue um quadro de análise das categorias elencadas: 
Gráfico 3: Categorias de análise e discursos da pergunta: Na sua opinião, a ideia da sustentabilidade é trabalhada em sua graduação? Se sim, de que forma isso ocorre; caso contrário, por que não?

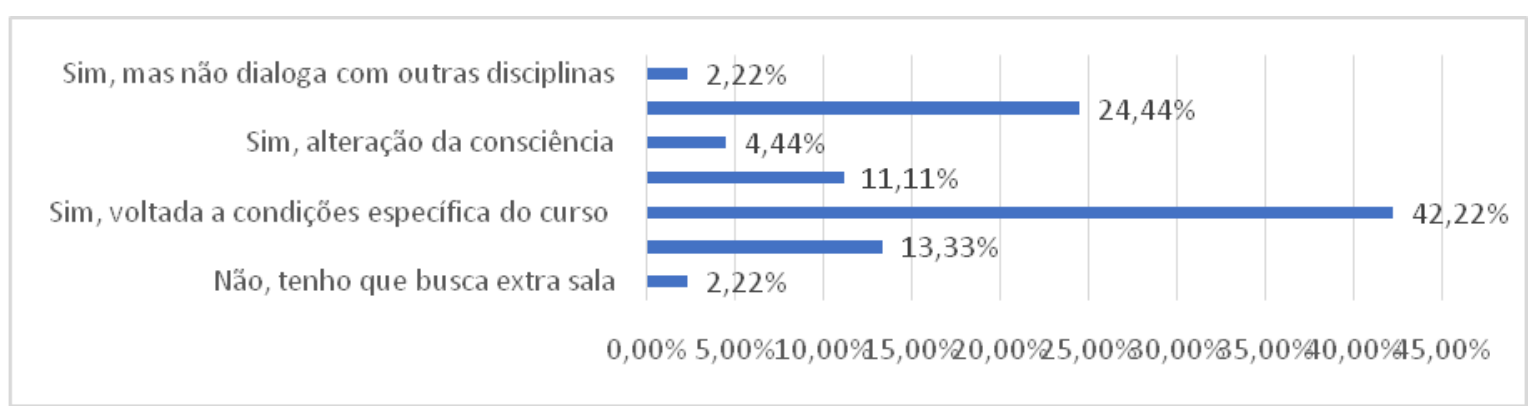

Fonte: Elaborado pelos autores com dados da pesquisa.

Para a maioria dos estudantes existem disciplinas de graduação que abordam o tema, a ideia é altamente compartilhada, apresentado grande amplitude nos discursos gerais, no entanto, as condições específicas do curso e não uma institucionalização como proposto, se torna condição de grande força, na percepção dos respondentes. Outro ponto a se destacar é que um grupo, com média força, tem a percepção de pouco aprofundamento sobre o tema, sobretudo nas relações teórico-práticas, a intensidade das ações pontuais e a pouca interação entre as disciplinas pode explicar um pouco deste cenário.

Entre os estudantes que não têm acesso ao tema em suas disciplinas no decorrer da graduação, a maioria destes percebem não existir tempo pedagógico hábil e espaços voltados a tais discussões, o que se torna preocupante, mesmo com baixa amplitude e força nos discursos gerais, em uma situação onde os respondentes foram escolhidos por já terem uma história de vida na instituição, tal percentual de estudantes que afirmam não ter acesso ao tema é preocupante, dada a missão e visão da própria instituição.Relacionando, para este momento das entrevistas, a percepção entre teoria e prática, na própria instituição, tomemos as seguintes categorias de análise e discursos síntese:

Quadro 4: Categorias de análise e discursos da pergunta: Existe, na sua percepção, alguma relação entre teoria e prática da sustentabilidade na Universidade Federal do Cariri? Se sim, como isso ocorre; caso contrário, por que não?

Categorias de análise -Discursos

Não, não existe relação teórico-prática - Na minha opinião não existe essa relação entre teoria e prática, por falta de empenho, nenhum projeto, não que eu me recorde agora de projetos que visem essa questão de sustentabilidade, eu não vejo, pelo menos nos corredores, dentro de sala de aula mesmo, prezar por essa teoria da sustentabilidade, enquanto prática, eu não vejo. Eu não consigo identificar nenhuma relação entre teoria e prática de sustentabilidade na universidade, porque a gente não vê nenhuma atividade sendo desenvolvida que seja acessível aos alunos, se existe eu 
não conheço, não vejo essa parte também de reciclar, na questão prática isso não é colocado de jeito nenhum para os alunos. Assim, não há o ensino, não há teoria, que seria demonstrada a partir de debates, né, que a universidade propusesse pra os alunos.

Não, as práticas são realizadas pelos estudantes - Com relação aos estudantes da universidade, eu acredito que a maioria é bem preocupada, o que se trabalha vem por parte dos alunos e não da própria universidade.

Não tenho ideia - Não tenho conhecimento, assim, de um trabalho sustentável que esteja sendo realizado aqui na faculdade, eu não tenho conhecimento nenhum da relação, mas pode existir e eu posso não conhecer. Se existe só se for no curso de pós-graduação em sustentabilidade, fora esse momento eu desconheço. Como eu não estou envolvido em nenhum projeto eu não tenho como opinar a respeito.

Se existe, desconheço, não há comunicação - Eu particularmente não enxergo essa ação sustentável de maneira clara, visível, abrangente e que se expressa para a comunidade acadêmica como um todo, se elas ocorrem não são divulgadas ao público, aos alunos e a gente não percebe nenhuma relação, de certa forma não tem como a gente perceber, não é muito divulgado digamos assim. Nunca vi, particularmente, não é uma coisa que chega pra todos, eu acredito.

Existe teoria, mas não a prática - Sim, quando a professora faz com que a gente pense na nossa profissão futura, métodos que podem trazer para nossas ações o melhor para o planeta, na prática mesmo eu ainda não observo tanto quanto eu observo na teoria. Só é abordado em uma cadeira e ainda é pouco, meu contato basicamente foi na teoria, na questão de explicar, questão de prática mesmo não tive essa experiência, no meu curso eu não tive esse contato prático com a sustentabilidade de nenhuma forma. Na teoria, no caso, é bem visto, mas na prática é pouco e deixa bastante a desejar.

Sim, existe relação teórico-prática - Sim, a parte teórica devido as aulas e na prática devido aos projetos que fornecem esses materiais, como o projeto que foi exposto pelo meu curso e colocado no pátio, que deixa toda a comunidade acadêmica ciente.

Sim, existe iniciativas pontuais - A única coisa que eu vejo aqui na prática relacionado a sustentabilidade é essa tendência a lixeira ser classificadas por material pra reciclagem, tem as plantinhas plantadas. Como eu digo, existe por causa do mestrado, mas na verdade é algo muito pouco, muito raso e que você não vê muita participação não.

Fonte: Elaborado pelos autores com dados da pesquisa.

A maioria dos discursos se referem ao distanciamento entre teoria e prática, na percepção dos respondentes, as categorias de análise nos auxiliam a compreender os motivos deste distanciamento. Os estudantes não conseguem enxergar, em sua maioria, esta relação teórico-prática, pela inexistência de projetos e ações que realizem tal interlocução, a falta de divulgação também é apontada, muitos destes simplesmente não sabem responder ou não observam tais relações, onde compreendemos tal limite como nocivo a formação, uma vez que ao confrontar suas ações cotidianas com as teorias estudadas, se toma por qualidade essencial do processo a produção de novos conhecimentos (TRAVASSO, 2001).

O reforço as práticas sustentáveis em nível discente e docente tendem a ser transformadoras, ofertando espaços reflexivos para a tomada de consciência ante a crise, sobretudo ambiental, a qual se inserem as discussões sobre sustentabilidade.

No entorno da discussão alguns estudantes percebem a teoria arraigada da prática, outros ainda percebem sua existência em ações pontuais, corrigir esse rumo torna necessária que não só as ideias e ações cheguem aos estudantes, mas também sua institucionalização, a promoção entre servidores e docentes, bem como servidores terceirizados, levando todo o tema a ser discutido pela comunidade educativa, não basta apenas a inserção de disciplinas no currículo, é sobretudo, uma ação política institucionalizada que enseja a possibilidade da ampliação de sua presença (TRAVASSO,

Rev. Eletrônica Mestr. Educ. Ambient. Rio Grande, v. 37, n. 3, p. 138-161, mai./ago. 2020. 
2001).Analisando a composição destas categorias, o seguinte gráfico resume os discursos síntese:

Gráfico 4: Categorias de análise e discursos da pergunta: Existe, na sua percepção, alguma relação entre teoria e prática da sustentabilidade na Universidade Federal do Cariri? Se sim, como isso ocorre; caso contrário, por que não?

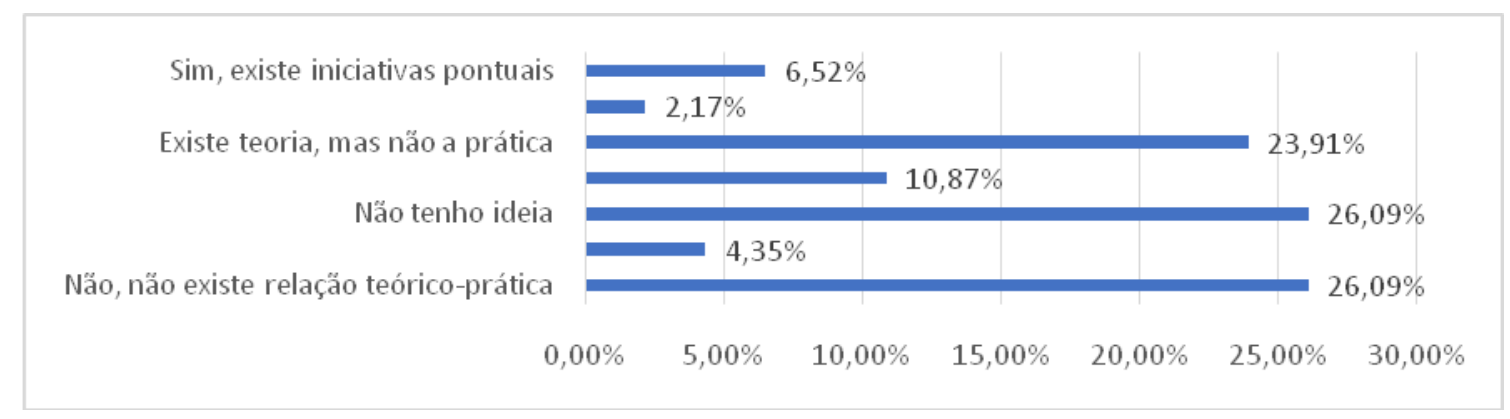

Fonte: Elaborado pelos autores com dados da pesquisa.

Amplamente difundida no todo, a percepção da não existência de relação teórico prática, tem maior força nos discursos analisados, o que nos leva a uma questão pedagógica eminente do campo da didática em repensar a forma como essa discussão tem sido inserida no currículo acadêmico, não basta apenas a inserção quantitativa de conteúdo, mas que eles tenham diferença substancial na formação dos estudantes.

As propostas que estão ligadas as metodologias ativas e a educação cooperativa podem nos apresentar melhores resposta a essa discussão, uma vez que são pautadas no ensino significativo, com forte apelo prática, bem como, ter em mente a escolha intencional por um paradigma frente a educação ambiental, mais próximo da prática visando, além disso, uma educação crítica.

A pergunta cabal, que melhor confere as intenções e objetivos deste estudo finaliza a série de entrevistas, segue abaixo as categorias de análise, bem como, cada um dos discursos síntese das percepções dos estudantes sobre "qual sua compreensão acerca do conceito de sustentabilidade":

Quadro 5: Categorias de análise e discursos da pergunta: De que forma você compreende a sustentabilidade? Nos fale com detalhes sobre esse tema. As questões foram elaboradas e testadas, com a participação de 10 estudantes da UFCA em amostragem aleatória. 
Percebe as dimensões da sustentabilidade - Então a sustentabilidade pra mim, nada mais é do que a agregação dos valores sociais, econômicos e ambientais; ela se organiza em algumas frentes, não tendo uma ligação só com o meio ambiente. A sustentabilidade tem várias perspectivas, a mais famosa é ambiental, mas que também pode relacionar com aspectos sociais, econômicos, educacionais, políticos; entendo a sustentabilidade como uma forma de trabalhar os recursos de forma geral, não só no sentindo ambiental, um modo de vivência em que se daria a questão de desenvolver economicamente prezando toda a questão da sociedade, tanto a parte econômica como a parte social. A gente precisa ter sustentabilidade nas instituições públicas, sustentabilidade no que concerne ao bom gasto do dinheiro público por exemplo.

Redução de impactos - Eu vejo a sustentabilidade como o método para reduzir o impacto ambiental, reduzir a produção de forma que a gente reutilize, minimizar os danos que seriam causados ao meio ambiente tanto a curto quanto à longo prazo, em todas as suas ações e também incentivar ações que possam preservar esse meio ambiente, medidas que possam amenizar os impactos que os humanos causam no planeta. Tudo que você tira, você aproveita o máximo, e tudo que você possa diminuir, você tem que diminuir o máximo. Sustentabilidade é você produzir com menor número, menor impacto possível no meio ambiente, a questão de você valorizar mais o que o meio ambiente nos oferece. Com a sustentabilidade a gente pode transformar essa questão das matérias que seriam perdidas pra reaproveita-las no nosso dia-a-dia, buscar por fontes renováveis, a questão de trabalhar melhor o recurso e tornar um projeto, tornar uma empresa, tornar o meio ambiente mais econômico; pensando nas questões do meio ambiente, pensando nas responsabilidades que a gente tem em cuidar do nosso ecossistema, de pensar em formas que não agridam tanto, sem tornar escassos os recursos naturais. O ser humano ter o próprio sustento sem prejudicar o meio ambiente, nem os seres humanos, minimizar ações antrópicas que destruam aquele meio ambiente, numa forma que possibilidade a subsistência do ser humano e o não esgotamento dos recursos naturais.

Consumo consciente - Acho que eu compreendo sustentabilidade como uma forma de reutilização de objetos descartáveis, para que a gente possa sempre fazer coisas com os recursos que nós temos e que essas coisas que a gente possa fazer a gente possa inovar e encontrar novos meios no sentido de reutilizar, de repensar novas formas, no gerenciamento dos recursos que temos e evitar gastos desnecessários. Uma possibilidade de subsistência do ser humano e uso dos meios de uma forma mais consciente, no reaproveitamento das coisas que são usadas e utilizar os recursos naturais para uma possibilidade de melhoria, de uso mais consciente, como a água, coisa que você extrai da natureza, que não prejudique o meio ambiente, que você consiga conciliar os dois, tanto a produção em si, como o meio ambiente.

Sustentabilidade para o bem-estar sistêmico - Eu compreendo a sustentabilidade como qualidade de vida, como meios de desenvolver atividades que promovam qualidade de vida e não só o crescimento, a ideia de que devemos cultivar o planeta de um jeito de não o agredir. Eu vejo como uma solução para muitos problemas, inclusive a saúde do planeta, inclusive nossa saúde, para que possa trabalhar e crescer ao mesmo tempo de forma segura, sem atrapalhar o meio ambiente, conseguindo viver harmoniosamente sem interferir de uma forma muito negativa naquele meio que você está inserido. É quando um ambiente consegue se suprir com apenas o que ele tem, seria a busca do equilíbrio entre o ser humano e o meio ambiente onde ele vive, a respeito do modo como podemos viver em harmonia com o meio ambiente, ideias que melhorem a vida das pessoas e do planeta, e das relações com o meio ambiente.

Não tem ideia - Tenho poucas noções sobre sustentabilidade, não saberia falar muito desse tema, não sei explicar. Sabe aquilo que você sabe e não sabe explicar?

Sustentabilidade é uma questão ambiental - A sustentabilidade é algo pensado em relação ao meio ambiente, pensando no futuro, olhando para o meio ambiente; ela é relacionada as questões do meio ambiente, a preservação do meio ambiente.

Compreende o conceito de sustentabilidade - Uma forma inteligente de crescimento, capaz de desenvolver, sem prejudicar as gerações futuras. É usufruir dos recursos de hoje, mas se preocupando com as gerações futuras e principalmente, não gastando tudo o que a natureza nos oferece e repondo também, sem retroceder no sentido ecológico, até porque deve existir sempre a preocupação com as gerações vindouras.

Fonte: Elaborado pelos autores com dados da pesquisa.

As dimensões da sustentabilidade são percebidas por um grupo de estudantes dentro do tema pesquisado, compreendidas como possibilidades de pesquisa, entender a sustentabilidade desarticulada do todo complexo da realidade se apresenta como um limite de interação e entendimento conceitual, mesmo que a maioria das pesquisas no Brasil esteja centrada nesse âmbito, existe a necessidade da crítica epistemológica, uma vez que, mesmo apenas no âmbito da pesquisa, a realidade não pode ser separada do todo em vistas a se compreender suas interações sob pena da perda de reflexões importantes e dados significativos (MORRIN, 2013; SANTOS, 2010). 
Analisando mais profundamente estes discursos, os projetos pedagógicos dos cursos $^{5}$ realmente estão centrados em tal dicotomia, que pode ser vista na literatura base apresentada, a maioria dos autores está centrada neste nível de compreensão dicotômico da realidade. Inclusive, digno de nota, mesmo sendo a UFCA uma instituição com missão e visão voltada a sustentabilidade, nem todos os projetos que constituem os cursos refletem esses princípios geradores.

Uma densa parte dos entrevistados centra suas percepções na redução de impactos e no consumo, estando interligadas diretamente ao fator ambiental proposto, sendo uma acepção rasa que não leva em conta as questões sociais. Não estamos aqui, contudo, apresentando um dado incomum, uma vez que, seja por conta das dicotomias ou do que julga o senso comum, normalmente a sustentabilidade é empregada como sinônimo de cuidado meio ambiente (ALIER, 2015; BOFF, 2015; SEQUINEL, 2002).

Apenas uma das categorias de análise se apresenta com relação ao bem-estar, ligada a uma preocupação com as atuais e as futuras gerações, de perspectiva social e também o cuidar com o planeta. Na perspectiva sistêmica são justamente estes os pontos principais da questão ambiental e a construção de uma sociedade mais justa, pautada na ética e na propensão a reconhecer os limites e possibilidades de um planeta finito, para que todos, as gerações atuais e futuras, possam gozar do bem-estar (BOFF, 2015).

Sintetizando estas análises o seguinte gráfico nos apresenta dados quantitativos da construção destes discursos:

Gráfico 5: Categorias de análise e discursos da pergunta: De que forma você compreende a sustentabilidade? Nos fale com detalhes sobre esse tema. As questões foram elaboradas e testadas, com a participação de 10 estudantes da UFCA em amostragem aleatória.

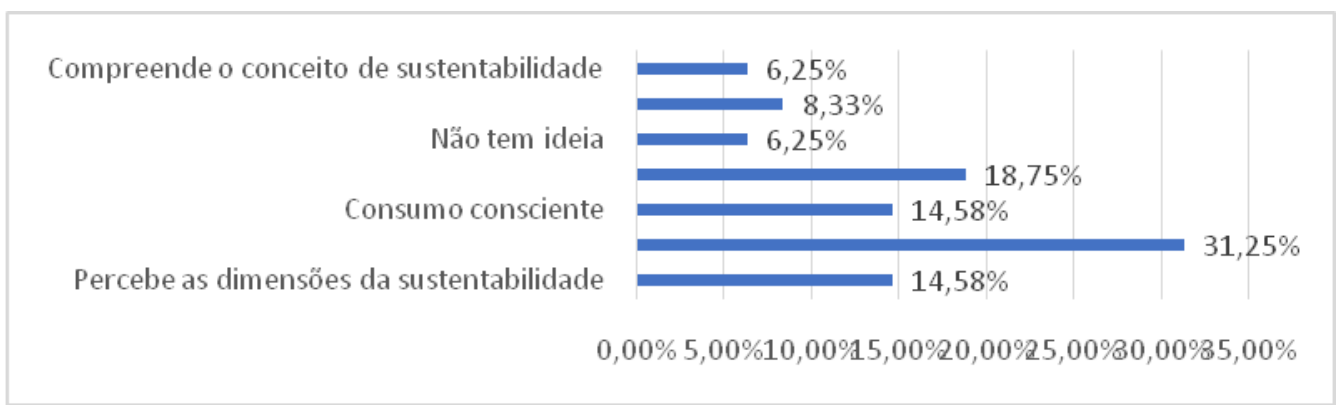

Fonte: Elaborado pelos autores com dados da pesquisa.

\footnotetext{
${ }^{5}$ Os projetos pedagógicos dos cursos podem ser acessados pelo site http://www.ufca.edu.br/portal/ensino.
} 
Bem distribuído no todo das ideias, com alta amplitude e grande força, a maioria dos respondentes compreende que a sustentabilidade é uma questão ambiental voltada a reduzir impactos, estando mesmo ligada a questão ambiental. Uma pequena parcela, de alta amplitude e baixa força, dos discursos analisados apresenta realmente a ideia de que a sustentabilidade está ligada apenas ao meio ambiente e também ao consumo consciente, ambas acabam se ligando e fortalecendo a categoria de redução de impactos por aderência discursiva.

Um pequeno grupo, de baixa intensidade e amplitude, compreende o conceito de sustentabilidade como posto ela OCF (2017) sendo uma ideia condensada em um pequeno grupo. Com alta força e baixa amplitude, um grupo coeso, mas pequeno de estudantes vêm a perceber as questões sociais dentro da sustentabilidade, esse é um ponto crítico, justamente pela ideia posta de sustentabilidade tratar eminentemente de um mundo melhor para todos, gerações atuais e futuras, onde se interligam e perpassam as questões políticas, sociais, ambientais, econômicas e educativas (OCF, 2017).

Explorando todas as ideias centrais, de todos os discursos analisados, sintetizamos um quadro que demonstra as questões das dimensões da sustentabilidade a partir da percepção dos estudantes. Achamos por bem tal análise, uma vez que estas dimensões fundamentam a base teórica dos estudantes da instituição:

Quadro 6: Percepção do conceito dimensional de sustentabilidade.

CURSOS DE GRADUAÇÃO

ADMINISTRAÇÃO PÚBLICA

ADMINISTRAÇÃO

BIBLIOTECONOMIA

COMUNICAÇÃO SOCIAL

DESIGN DE PRODUTOS

ENGENHARIA CIVIL

ENGENHARIA DE MATERIAIS

FILOSOFIA

MUSICA

MÉDIA DE PERCEPÇÃO NOS

DISCURSOS POR CURSO
DIMENSÕES PERCEBIDAS DA SUSTENTABILIDADE

\begin{tabular}{lllll}
\hline Política & Ambiental & Social & Economica & Educacional \\
$1,28 \%$ & $3,85 \%$ & $6,41 \%$ & $6,41 \%$ & $1,28 \%$ \\
$1,28 \%$ & $5,13 \%$ & $1,28 \%$ & $3,85 \%$ & $0 \%$ \\
$0 \%$ & $2,56 \%$ & $1,28 \%$ & $1,28 \%$ & $0 \%$ \\
$0 \%$ & $5,13 \%$ & $2,56 \%$ & $1,28 \%$ & $0 \%$ \\
$0 \%$ & $3,85 \%$ & $0 \%$ & $0 \%$ & $0 \%$ \\
$0 \%$ & $14,10 \%$ & $5,13 \%$ & $7,69 \%$ & $0 \%$ \\
$1,28 \%$ & $6,41 \%$ & $2,56 \%$ & $2,56 \%$ & $2,56 \%$ \\
$0 \%$ & $3,85 \%$ & $1,28 \%$ & $1,28 \%$ & $0 \%$ \\
$0 \%$ & $1,28 \%$ & $0 \%$ & $1,28 \%$ & $0 \%$ \\
$3,85 \%$ & $46,15 \%$ & $20,51 \%$ & $25,64 \%$ & $3,85 \%$
\end{tabular}

Fonte: Elaborado pelos autores com dados da pesquisa. 
Ao analisarmos todos os discursos reunidos neste momento da pesquisa, notemos, de forma geral, que a percepção das dimensões da sustentabilidade não se mostra salutar a constituição de um conhecimento integral e mais próximo da realidade. Apenas os cursos de engenharia de materiais e administração pública demonstram compreender, no conjunto dos discursos, a amplitude da discussão.

O objetivo de dividir as discussões em grupos, aos quais os autores conceituam como dimensões/pilares da sustentabilidade, é a melhor compreensão de suas relações entendendo que essas dimensões/pilares não são separadas do todo (SACHS, 2008; VEIGA, 2008; SACHS, 2000; JACOBI, 1999), esta análise, dentro do espaço que se propõem a estudar, demonstra que os intentos dos pesquisadores que seguem tais linhas são limitados no que tange a relação com a educação e a construção do conhecimento por parte do estudante.

O que ocorre de fato é que a maioria das percepções apresentadas, ao tomar posse das ideias ante sua dicotomização, acaba por priorizar a dimensionalidade ambiental, seguida da econômica e, posteriormente da social, onde as dimensões políticas e educacionais (JACOBI, 1999) pouco são percebidas, além de outras dimensões emergente na discussão, como a cultura.

Na realidade da UFCA, tal recorte não faz sentido, uma vez que a multiplicidade do tema está presente a uma diversidade de cursos, que segundo a missão e a visão da instituição devem permear todos os campos. Não é apenas a base curricular, a estrutura metodológica, a didática, as ações propostas e a institucionalização que necessita ser revistas e repensada, mas também as bases teóricas e epistemológicas no bojo da discussão acadêmica.

Outro fator que pode estar influenciando é a pontualidade das ações, sejam por serem disciplinas isoladas, fragmentadas no decorrer da graduação, ou mesmo ações pontuais com pouca visibilidade. Os discursos compartilhados com grande amplitude e intensidade, demonstram que as questões ambientais são o cerne do conceito de sustentabilidade, justamente pela falta de aprofundamento em sala de aula e também a falta da relação teórico-prática.

Urge a necessidade de renovação, em vistas a uma educação integral, voltada a formulação de uma educação crítica, colaborativa e humana, permeada pelos sentidos necessários à sustentabilidade como missão maior da educação superior na UFCA.

\section{Conclusão}

Rev. Eletrônica Mestr. Educ. Ambient. Rio Grande, v. 37, n. 3, p. 138-161, mai./ago. 2020. 
A educaçãosuperior, na perspectiva crítica, colabora para pensarmos a prática social de forma mais inclusiva e próxima ao real, estabelecendo nas interações sociais sua forma de agir e pensar. Floresce a necessidades de pensarmos novos rumos para problemas que afligem a sociedade contemporânea, buscando refletir sobre as possibilidades que a educação apresenta para essas problemáticas, fomentando uma sociedade mais justa para as atuais e as futuras gerações.

Em vistas a perceber se existem lacunas no processo que tange a discussão na UFCA, entrevistamos estudantes da instituição, com ao menos um ano na IES, buscando suas percepções acerca do tema.

O principal espaço de contato inicial com o tema sustentabilidade é a escola, são as primeiras relações na prática escolar que estão mais evidenciadas, os participantes também apresentam a mídia e a UFCA como promotoras iniciais dessa discussão. O que demonstra a importância dos espaços educativos, não só em divulgar, mas de estabelecer processos educativos que contemplem a temática.

No que tange a influência da UFCA para a discussão sobre o tema, os estudantes percebem ser superficial, alicerçada em algumas disciplinas de graduação e a condições muito especificas dos cursos de graduação e alguns eventos. Essas percepções demonstram a pontualidade que o tema é tratado, tendo em vista ser missão e visão da IES, não estando se quer presente em todos os projetos pedagógicos dos cursos de graduação dos participantes da pesquisa.

A abordagem da sustentabilidade nas disciplinas de graduação da instituição é percebida como momentânea e pouco aprofundada entre os participantes que dizem existir tal discussão, poucos são os que percebem o aprofundamento nas disciplinas, em grande parte essa questão passa de superficial a não abordada.

Compreendemos um problema curricular, onde os estudantes denotam o pouco tempo ou a falta de espaço e divulgação do tema, como fatores que incidem diretamente para a pouca abordagem. A revisão dos currículos e das ações propostas pela instituição pode ser norteadora de mudanças, cabendo estudos mais aprofundados em cada realidade específica à cada curso de graduação.

Quando questionados sobre as relações teórico-práticas existentes na instituição sobre o tema, a maioria dos estudantes afirma não existirem, estando mais em nível teórico, relegado a unas poucas disciplinas e eventos pulverizados no calendário acadêmico.

Rev. Eletrônica Mestr. Educ. Ambient. Rio Grande, v. 37, n. 3, p. 138-161, mai./ago. 2020. 
Quando questionamos sobre o entendimento dos estudantes sobre a sustentabilidade pudemos compreender melhor os discursos apresentados, para a maioria dos estudantes a sustentabilidade é uma questão ambiental voltada a mitigar problemas que possam impactar o meio ambiente, ligada também ao consumo consciente, entendido como aquele que ocasione mínimo impacto ao meio ambiente. Sustentabilidade, na percepção dos estudantes, é uma questão apenas ambiental.

O tema bem-estar também aparece, mas de forma muito concentrada em alguns discursos, ligada a qualidade de vida, trabalho e saúde, na compreensão desse grupo as ações e estudos devem convergir a um maior significado do tema que possa influenciar a vida das pessoas.

Entre as percepções dos estudantes compreendemos que a sustentabilidade está pautada, epistemologicamente, como categorias, pilares ou dimensões, dicotômicos da realidade, o que dificulta uma visão integral do tema que possa contribuir para relações teórico-práticas. Ao analisarmos todos os discursos reunidos na pesquisa, concluímos que a percepção das dimensões da sustentabilidade não se mostra salutar a constituição de um conhecimento integral e mais próximo da realidade.

Uma das causas é o recorte presente nos planos de ensino apresentado pelos projetos pedagógicos dos cursos, a literatura utilizada reúne autores, teorias e estudos alinhados a essa dicotomia, ao qual não faz sentido, visto a multiplicidade do tema presente a uma diversidade de cursos, que segundo a missão e a visão da instituição devem permear todos os campos. Não é apenas a base curricular, a estrutura metodológica, a didática e as ações propostas, a instituição necessita revisar e repensar também as bases teóricas e epistemológicas da discussão acadêmica.

Outro fator geral influencia a discussão é a pontualidade das ações, sejam por serem disciplinas isoladas, fragmentadas no decorrer da graduação, ou mesmo ações pontuais com pouca visibilidade, os discursos compartilham com grande amplitude e intensidade as questões ambientais como cerne do conceito de sustentabilidade, justamente pela falta de aprofundamento e relação teórico-prática.

A partir dos dados coletados, sistematizados e analisados percebemos a necessidade de compor a discussão no âmbito social, relacionando a influência da sustentabilidade ante a questões sociais, a partir do estabelecimento de relações mais próximas a realidade dos estudantes.

A UFCA é uma das mais jovens instituições de Ensino Superior a nível Federal do Brasil, nasce inserindo o desenvolvimento sustentável em sua missão e visão, não apenas 
na perspectiva retórica, oferecendo ações e inserindo o tema no currículo. Por ser uma das novíssimas IES é normal a necessidade de amadurecimento da discussão, em nível teórico e prático, que deve ser fortalecido, o presente estudo apresenta variadas conjecturas que podem apoiar esse amadurecimento.

Para estudos futuros estamos interessados em analisar a influência do Programa de Pós-Graduação em Desenvolvimento Regional Sustentável (PRODER/UFCA) e outras atividades pontuais, principalmente ligadas a extensão e cultura, desenvolvidas pela instituição. Perquirir ações e ações do conhecimento que visam a difusão do desenvolvimento sustentável podem contribuir para que outras IES possam se inserir nas discussões e contribuam para uma sociedade mais justa e inclusiva.

\section{Referências}

ALIER, Joan Martínez. O ecologismo dos pobres: conflitos ambientais e linguagens de valoração. 2ed. São Paulo: Editora Contexto, 2015.

ANTUNES, Jeferson; NASCIMENTO, Verônica Salgueiro do; QUEIROZ, Zuleide Fernandes de. Educação para sustentabilidade, interdisciplinaridade e as contribuições da mediação para a construção coletiva do conhecimento. Rev. Eletrônica Mestr. Educ. Ambient. Rio Grande, v. 35, n. 1, p. 260-278, jan./abr. 2018.

ANTUNES, Jeferson; NASCIMENTO, Verônica Salgueiro do; QUEIROZ, Zuleide Fernandes de. Narrativa crítica acerca do desenvolvimento sustentável: quais relações podemos estabelecer?. Rev. Eletrônica Mestr. Educ. Ambient. Rio Grande, v. 34, n. 2, p. 57-65, maio/ago. 2017.

ANTUNES, Jeferson; RIBEIRO, Verônica; ARRAIS, Estêvão; MOREIRA, Raniere. A política de reestruturação e expansão das universidades federais no Brasil: Um olhar sobre o curso de Administração Pública da Ufca. In: ANAIS I Simpósio de Pesquisa e Inovação da UFCA. Juazeiro do Norte: UFCA, 2015.Disponível em $<$ https://ebooks.ufca.edu.br/catalogo/anais-do-i-sinapi/> acesso em 18-02-2018 às 08:00 horas.

BERNHEIM, Carlos Tünnermann; CHAUÍ, Marilena de Souza. Desafios da universidade na sociedade do conhecimento: cinco anos depois da conferência mundial sobre educação superior. Brasília: UNESCO, 2008.

BOFF, Leonardo. Sustentabilidade: O que é - O que não é. 4ed. Rio de Janeiro: Editora Vozes, 2015

CARVALHO, Isabel Cristina de Moura. Educação ambiental: a formação do sujeito ecológico. Cortez Editora, 2017. 
CASTANHEIRA, Nelson Pereira. Estatística aplicada a todos os níveis. Curitiba:

Editora Intersaberes, 2012.

DMESSXXI. Declaração Mundial sobre o Ensino Superior para o Século XXI (1998). Disponível em <http://www.direitoshumanos.usp.br/index.php/Direito-a-

Educa \%C3\%A7\%C3\%A3o/declaracao-mundial-sobre-educacao-superior-no-seculo-xxivisao-e-acao.html> acesso em 18-02-2017 às 08:00 horas.

EDWARDS, Rosalind; HOLLAND, Janet. What is Qualitative Interviewing?. Londres: BloomsburryAcademic, 2013.

FLICK, Uwe. Introdução a pesquisa qualitativa. 3ed. Porto Alegre: Artmed, 2009.

FLORIANI, Dimas. Marcos Conceituais do Desenvolvimento da Interdisciplinaridade. In: PHILIPPI, Arlindo Jr.; TUCCI, Carlos E. Morelli; HOGAN, Daniel Joseph; NAVEGANTES, Raul. Interdisciplinaridade em Ciências Ambientais. São Paulo: Signus Editora, 2000.

JACOBI, Pedro. Meio ambiente e sustentabilidade. O Município no século XXI: cenários e perspectivas. Cepam-Centro de Estudos e Pesquisas de Administração Municipal, p. 175-183, 1999.

LDB. Ministério de Educação e Cultura. LDB - Lei no 9394/96, de 20 de dezembro de 1996. Estabelece as diretrizes e bases da Educação Nacional. Brasília: MEC, 1996.

LEFEVRE, Ana Maria; LEFEVRE, Fernando. Pesquisa de representação social: Um enfoque qualiquantitativo. 2ed. Brasília: Liber Livro, 2012.

MORRIN, Edgar. A Via para o futuro da humanidade. Rio de Janeiro: BERTRAND BRASIL, 2013.

OCF. Our commun Future: Report of the World Commission on Environment and Development. Disponível em < http://www.un-documents.net/our-common-future.pdf> Acesso em: 04-03-2017 às 10:00:00.

SACHS, Ignacy. Desenvolvimento includente, sustentável e sustentado. Rio de Janeiro: Garamond, 2008.

SACHS, Ignacy. Caminhos para o desenvolvimento sustentável. Rio de Janeiro: Editora Garamond, 2000.

SANTOS, Boaventura de Santos. Um discurso sobre as ciências. 7ed. São Paulo: Editora Cortez, 2010.

SEQUINEL, Maria Carmen Mattana. Cúpula mundial sobre desenvolvimento sustentável - Joanesburgo: entre o sonho e o possível. Revista Análise Conjuntural, v.24, n.11-12, p.12, nov./dez. 2002.

TRAVASSOS, Edson GOMES. A educação ambiental nos currículos: dificuldades e desafios. Revista de biologia e ciências da terra, v. 1, n. 2, 2001. 
VEIGA, José Eli da. Desenvolvimento sustentável: o desafio do Século XXI. 3ed. Rio de Janeiro: Garamond, 2008.

Submetido em: 01-01-2020.

Publicado em: 21-08-2020. 